\title{
Methode zur directen Bestimmung der Thonerde neben Eisenoxyd.
}

\author{
Von Ed. Donath, \\ 7. k. Adjunct der Lehrkanzel für Chemie und Probirkunde an der Bergakademie in Leoben.
}

(Vorgelegt in der Sitzung am 14. October 1880.)

Bekanntlich wird in den meisten Fällen die Thonerde neben Eisenoxyd nicht direct bestimmt, sondern aus der Gesammtmenge der beiden Oxyde und der Menge des auf irgend eine Art massanalytisch bestimmten Eisenoxydes ermittelt. Die Titrirmethoden des Eisens sind zwar im Allgemeinen genan; es kann jedoch diese indirecte Bestimmung der Thonerde dann mit einer grösseren Ungenauigkeit behaftet sein, wenn die Fehler bei der Bestimmung der Gesammtmenge und der Menge des Eisenoxyds sich summiren. Dass dennoch nur selten eine factische Trennung und Bestimmung der Thonerde erfolgt, liegt in den Schwierigkeiten, mit denen eine solche verknüpft ist. Denn genaue Pesultate liefert nur die Schmelzung der beiden Oxyde im Silbertiegel mit Ätzkali und Ausziehen des löslichen Aluminates mit Wasser. Allein die Anwendung eines Silbertiegels ist, wie auch Rose in seinem bekannten Werke betreffenden Ortes ${ }^{1}$. bemerkt, immer unangenehm; zudem geht dabei zuletzt beim Waschen mit kochendem Wasser das Eisenoxyd gern durchs Filter.

In Folgendem beschreibe ich eine Methode, welche gestattet, die Thonerde direct neben Eisenoxyd, jedoch nicht letzteres gleichzeitig, zu bestimmen und deren Anwendung sich hauptsäehlich dann empfiehlt, wenn man eine Controle der indirecten Bestimmung haben will.

Bekanntlich besitzt das Aluminium nicht das Vermögen Cyan oder gepaarte Cyanverbindungen zu bilden, während diese Fähigkeit in hohem Grade dem Eisen zukömmt. Fügt man zu

1 6. Auflage, Seite 105 . 
einer das Eisen als Oxydul enthaltenden Lösung Cyankalium im Überschuss hinzu, so löst sich der anfangs gebildete, braungelbe Niederschlag unter Bildung von Ferrocyankalium vollständig wieder auf, besonders leicht beim Erwärmen und gleichzeitiger Anwesenheit von etwas Ätzkali. ${ }^{1}$ Auch Thonerde wird von einem Überschuss von Cyankalium genau so wie von $\ddot{A}$ tzkali gelöst, ohne dass jedoch eine ähnliche Umsetzung derselben erfolgt und zersetzt man das Cyankalium durch blossen Zusatz ron Essigsäure oder irgend einer Mineralsäure, so lässt sich die Thonerde durch ihre gewöhnlichen Fällungsmittel, wie z. B. Ammoncarbonat vollständig wieder abscheiden. Auf dieses Verhalten ist die Methode zur directen Bestimmung der Thonerde basirt, deren Ausführung im Folgenden beschrieben ist.

Die Eisenoxyd und Thonerde enthaltende Lösung wird eventuell auf ein kleineres Volum, ungefähr 100 CC. eingedampft, oder man nimmt zweckmässiger einen entsprechenden aliquoten Theil der Lösung. Nun wird die freie Säure durch Zusatz von Ammoniak grösstentheils abgestumpft, so dass nur noch eine ganz geringe Menge derselben vorhanden ist. Anderseits erhitzt man in einem geräumigen Becherglase eine mit etwas Ammoniak versetzte Lösung ron übersehiissigem Cyankalium (15-20 Grm. auf $0 \cdot 1-0 \cdot 3 \mathrm{Gr}$. Eisenoxyd) bis fast zum Kochen; das Volumen der Cyankaliumlösung soll mindestens doppelt so gross sein, als das der Eisenoxyd- und Thonerdelösung. $\mathrm{Zu}$ dieser hat man inzwischen unter Umrüluren so lange von einer concentrirten Lösung von unterschwefligsaurem Natron zugefügt, bis dieselbe dureh vollständige Reduction des Eisenoxydes zu Eisenoxydul ganz farblos geworden ist. Sie wird nun ganz langsam (unter schliesslichem Nachspïlen) in die heisse Cyankaliumlösung eingegossen and diese durch ungefähr eiue Minute noch erwärmt. Die entstandene Lösung soll eine gelbe, etwas ins Grünliche gehende, aber keine braunliche Färbung besitzen; sie wird durch sofortiges Einstellen in kaltes Wasser möglichst rasch und vollständigst abgekiihlt. Man setzt sodann Essigsäure zu, bis die Flüssigkeit deutlich saner reagirt und schliesslich sofort Ammoncarbonat bis zur alkalischen Reaction. Der entstandene Niederschlag von

1 Siehe auch Fresenius, Journal für prakt. Chemie. 74. Bd., s. 252 . 
Thonerde wird vollständig absitzen gelassen, sodann aber unverweilt abfiltrirt und mit kochendem Wasser vollständig ausgewaschen. Die so erhaltene Thonerde ist dann fast völlig weiss, wenn in der ursprïnglichen Lösung relativ wenig Eisen vorhanden war; bei grossem und überwiegendem Eisengehalt ist sie aus später anzufïhrenden Gründen meistens schmutzig gelbgrünlich gefärbt.

Ist der Niederschlag rein weiss, so kann er sofort geglüht und gewogen werden; im entgegengesetzten Falle digerirt man sofort Filter mit Niederschlag mit heisser verdinnter Salzsäure (1:4), wodurch die Thonerde gelöst wird, während die die Färbung bedingenden Eisencyanide, dabei in einen berlinerblauartigen Körper übergehend, ungelöst bleiben. Nach einigem Absitzen filtrirt man die Lösung ab und bestimmt in derselben die Thonerde mit Ammoniak in bekannter Weise.

Zur Beurtheilung der Verwendbarkeit dieser Methode mögen folgende Belegresultate dienen:

$30 \mathrm{CC}$. einer Alaunlösung gaben, mit Ammoniak entsprechend gefällt, $0.1200 \mathrm{Grm}$. Thonerde, mit Ammoncarbonat (in der Kälte) $0 \cdot 1196 \mathrm{Grm}$.

Mit dieser Lösung und einer Eisenchloridlösung, die in 25 CC. $0 \cdot 1420 \mathrm{Gr} . \mathrm{Fe}_{2} \mathrm{O}_{3}$ enthielt, wurden Mischungen hergestellt, enthaltend:

1. $0.0800 \mathrm{Grm} . \mathrm{Al}_{2} \mathrm{O}_{3}$ und $0 \cdot 1420 \mathrm{Grm} . \mathrm{Fe}_{2} \mathrm{O}_{3}$.

2. $0.0800, " n ", " n$

3. $0 \cdot 1200 ", \quad " \quad " \quad " \quad " n$

4. $0 \cdot 1600 ", \quad ", " n, "$,

5. $0 \cdot 1200 " n, 0 \cdot 2840 ", n$

6. $0 \cdot 1200 ", \quad " 0 \cdot 4260 " n, "$

7. $0 \cdot 1200 ", \quad " \quad " \quad "$

Dieselben lieferten nach der beschriebenen Methode:

1. 0.0814 Grm. $\mathrm{Al}_{2} \mathrm{O}_{3}$.

2. $0.0816 " n$

3. $0.1222 " n$

4. $0 \cdot 1612 " n$

5. $0 \cdot 1255 " n$

6. $0.1253 "$ "

7. $0 \cdot 1280 " n$ 
D o n a th. Methode z. direct. Bestimmung d. Thonerde etc.

Die Niederschläge 1 bis inclusive 4 waren weiss, nach dem Glïhen kaum bemerkbar gelblich gefärbt; die anderen waren schmutzig und nach dem Glihhen stark gelblich gefärbt. Bei drei weiteren Versuchen mit Mischungen, enthaltend $0 \cdot 1200 \mathrm{Grm}$. $\mathrm{Al}_{2} \mathrm{O}_{3}$ und $0 \cdot 2840 \mathrm{Grm} . \mathrm{Fe}_{2} \mathrm{O}_{3}$, wurden die mit Ammoncarbonat erhaltenen Niederschläge nach dem Auswaschen sofort, wie angeführt, mit heisser, verdünnter Salzsäure behandelt und in der abfiltrirten Lösung die Thonerde mit Ammoniak bestimmt.

Erhalten wurden:

$$
\begin{array}{llll}
\text { 1. } & 0.1210 & \mathrm{Grm} . & \mathrm{Al}_{2} \mathrm{O}_{3} \\
\text { 2. } & 0 \cdot 1208, " & n \\
\text { 3. } & 0 \cdot 1190 \quad " &
\end{array}
$$

Es ist ersichtlich, dass, wie bereits angeführt, bei grösserem Eisengehalte der Lösung auch die Resultate der Thonerdebestimmung zu hoch ausfallen; es rührt dieses gewiss von der grossen Veränderlichkeit des vorhandenen Ferrocyanammoniums her, welches bekanntlich beim Abdampfen der Lösung ja auch beim längeren Stehen derselben an der Juft sich unter Abscheidung von Eisencyaniden zu zersetzen beginnt; desshalb ist die vorgeschriebene Schnelligkeit der Ausfithrung nothwendig. Bei geringeren Eisengehalten und genauester Befolgung der angegebenen Massregeln gibt die Methode jedoch hinreichend genane Resultate, sodass sie sich sowohlzur Bestimmung der Thonerde an und für sich als zur Controle der indirecten Bestimmung eignet. 